\title{
Servir bem para servir sempre? Técnica, mercado e o ensino de história pública
}

\author{
Serve Well to Always Serve? Technique, \\ Market and the Teaching of Public History
}

Ricardo Santhiago*

\section{Resumo}

$\mathrm{O}$ artigo investiga um dos pilares da história pública nos Estados Unidos: os programas de pós-graduação especializados, surgidos em meados de 1970 como resposta à crise empregatícia que historiadores enfrentaram naquele período. Tendo em vista os recentes movimentos de internacionalização da história pública e a criação de novos programas que seguem os moldes americanos, bem como o aparecimento de textbooks deliberadamente orientados à instrução de novos praticantes, discutem-se, também, as particularidades de experiências brasileiras em história pública, pouco afeitas ao modelo estadunidense, baseado na ideia de que a história pública constitui um campo disciplinar separado e que demanda formação profissional específica.

Palavras-chave: história pública; história aplicada; ensino superior.

\begin{abstract}
The article explores a pillar of public History in the United States: the specialized graduate programs, which emerged in the mid-1970s as a response to the employment crisis historians faced by then. In view of recent movements for the internationalization of public History and of the creation of new programs that follow the US experience, as well as the appearance of textbooks oriented to new practitioners' training, the article discusses the particularities of Brazilian experiences in public History, which holds little resemblance to the US major model, based on the idea that public History constitutes a separate disciplinary field and demands a specific training.
\end{abstract}

Keywords: public History; applied History; higher education.

\footnotetext{
* Universidade Federal de São Paulo (Unifesp), São Paulo, SP, Brasil. rsanthiagoc@gmail. com
} 


\section{ENSINANDO HISTÓRIA PÚBLICA}

Em 1999, em um ensaio chamado "Becoming a Public Historian" [Tornando-se um historiador público], a então diretora do Programa de História Aplicada da University of South Carolina, Constance B. Schulz, escrevia: "Como é que alguém se torna um historiador público? Alguns achariam um tanto irônico que, para se tornar um historiador público no final do século XX, um dos meios mais efetivos seja buscar formação dentro da academia" (Schulz, 1999, p. 23). "Alguns", quem sabe; certamente não todos. Menos ainda os leitores da própria Schulz, então introduzidos a um enredo otimista sobre a expansão do campo profissional e acadêmico da história pública nos Estados Unidos. A autora, afinal, escrevia mais de 20 anos depois da eclosão do célebre movimento, capitaneado pelo historiador ambiental Robert Kelley, que ofereceu um nome e ajudou a dar propósito e legitimidade para a atuação de historiadores fora do âmbito do ensino básico ou superior.

Professor do campus de Santa Bárbara do sistema da University of California, Kelley nutriu-se àquela altura de sua própria experiência para argumentar em favor do "emprego de historiadores e do método histórico fora da academia”, conforme sintetizou em texto seminal (Kelley, 1978, p. 16). Ele vinha atuando exitosamente como consultor e perito especializado em questões relacionadas a direitos aquíferos; assim, estava em posição de concluir que as habilidades necessárias para esse tipo de atividade, como empregado do estado da Califórnia, eram as mesmas que o historiador era treinado a desenvolver: pesquisa, análise e interpretação. Tais habilidades, argumentava Kelley, deveriam ser aproveitadas tanto no setor privado quanto no setor público, não apenas no campo então mirrado do ensino superior e da pesquisa acadêmica.

As circunstâncias em que essa argumentação ressoou e se transformou eram de fato mobilizadoras. O declínio nas taxas de crescimento e a inoportuna combinação entre inflação e desemprego que sucederam a crise do petróleo de 1973 formavam o fundo contra o qual uma crise específica no sistema universitário americano se colocava. A vertiginosa expansão de programas de pós-graduação, muitos deles financiados por fundações privadas, já havia desenhado, entre fins dos anos 1950 e início da década de 1970, uma encruzilhada: a formação de um número de doutores desproporcional à capacidade de absorção das instituições de ensino superior. A ela justapôs-se a diminuição 
dramática de matrículas nos cursos de graduação em História, que reduziu ainda mais o corpo docente nesses departamentos e impossibilitou algumas universidades de oferecerem tenure, como é chamada a estabilidade profissional naquele país, aos seus professores (Fishel Jr., 1986).

Com isso, muitos programas de pós-graduação em História reduziram o número de vagas disponíveis - e a American Historical Association (AHA) chegou a recomendar que os coordenadores desses programas enviassem aos candidatos aprovados, com a carta de boas-vindas, outra carta advertindo os estudantes sobre as precárias perspectivas de emprego na área (Novick, 1988). Entre 1970 e 1982, o número de bacharéis em História nos Estados Unidos foi reduzido em 60\% (Leffler; Brent, 1990). O diagnóstico desanimador de que o passado se tornara objeto de menor interesse da sociedade americana representou, entretanto, um impulso para que, em 1976, a AHA e a Organization of American Studies (OAS) se juntassem em um esforço comum, fundando o National Coordinating Committee for the Promotion of History [Comitê Coordenador Nacional pela Promoção da História], que visava revigorar o interesse público - especialmente de jovens estudantes - na história, e a confiança nos historiadores (Miller, 1998).

Dentre as diferentes percepções e iniciativas que emergiram a partir dessa coalizão, destacou-se o gesto de Robert Kelley, ao reiterar a prerrogativa do historiador como intérprete do passado e sua função social indispensável em uma sociedade em crise. Kelley insistia, por um lado, na premência da manutenção dos quadros e dos programas existentes em universidades; e, por outro, na formulação de "carreiras alternativas" para os historiadores. A preocupação com os caminhos pelos quais a sociedade americana vinha formando sua cultura histórica (antes por meio de bens culturais de ampla circulação do que em escolas e universidades) e o fortalecimento da interlocução com colegas que trabalhavam em agências governamentais e em sociedades históricas locais (realizando trabalhos de boa qualidade) eram objeto de igual atenção. Sob a etiqueta Public History, as resoluções de um e do outro problema pareciam encaminhadas.

\section{UMA IDEIA, UM MOVIMENTO}

A ironia para a qual Constance B. Schulz sinalizou pode abrir caminho, no entanto, para outra leitura dos resultados do movimento americano de 
história pública. Criado com o objetivo manifesto de alargar as perspectivas profissionais dos historiadores, ele pode ser entendido também como uma profecia que se autorrealiza. Não há dúvidas de que um de seus maiores êxitos foi criar a si mesmo: a toda uma área de especialidade acadêmica, que nos Estados Unidos inclui centenas de postos de trabalho em universidades, periódicos especializados, séries de livros em editoras importantes, congressos que movimentam dezenas de milhares de dólares, rubricas em agências de financiamento e uma associação científica com orçamento invejável.

No coração desse novo nicho estão os programas de pós-graduação em história pública. O primeiro deles foi fundado em Santa Bárbara por Robert Kelley, que obteve um grant da Rockefeller Foundation para desenvolver um programa de estudos voltado a promover a associação entre as habilidades do historiador e a formulação de políticas públicas. Seu parceiro na empreitada - que ambicionava instalar um programa de alcance nacional - foi o especialista em políticas públicas, e também historiador, G. Wesley Johnson. O sentido de "público" que os movia não era enunciado, mas estava implícito no objetivo da criação conjunta: auxiliar historiadores a transporem suas habilidades para trabalhos realizados fora da universidade. "Público" seria, então, não o mundo social de forma ampla, mas o conjunto de todos os indivíduos e instituições que pudessem servir-se do trabalho do historiador.

Se o background de Kelley e Johnson sugeria uma circunscrição ao universo da política pública, sua proposição sinalizava para uma variedade de clientes que poderiam ser atendidos pela disciplina histórica. Como Johnson relembrou duas décadas depois, o discurso criado por eles indicava "que historiadores possuíam habilidades que poderiam ser usadas para benefício público, seja em empresas, no governo, em fundações, em sociedades históricas, ou onde quer que fosse" (Johnson, 1999, p. 168) - não se excluindo daí, por exemplo, organizações privadas que desejassem empregar historiadores (alegadamente, historiadores públicos) para organizar seus documentos e mantê-los estritamente fechados e longe do público.

O êxito na formação da primeira turma de Santa Bárbara - que angariou a candidatura de alunos bem qualificados e, como Kelley e Johnson desejavam, de diversas partes dos Estados Unidos - ensejou a persecução do mesmo objetivo por outras universidades espalhadas pelo país. Entre os pioneiros e ativos, estão os programas da Arizona State University (criado em 1980)² e da 
New Mexico State University (em 1983). ${ }^{3}$ Em 1985, eram 50 programas em atividade nos Estados Unidos, em departamentos de história de faculdades e universidades públicas e privadas; em 2008, mais de 110. ${ }^{4}$ Nos dias atuais, contabilizam-se cerca de 220 programas no mundo todo, aproximadamente 200 deles na América do Norte, e os demais predominantemente em outros países de língua inglesa. Nos últimos anos, eles começaram a se expandir pela Europa, em países como Itália e França, e pela Ásia (Cauvin; Noiret, 2017; Ashton; Trapeznik, 2019).

A constituição e a consolidação de um aparato institucional alimentou esse crescimento. Idealizado em 1979 e formalizado no ano seguinte, o Conselho Nacional de História Pública, ou National Council for Public History $(\mathrm{NCPH})$, tornou-se o espaço de agregação e centralização de uma rede intelectual, inicialmente composta por acadêmicos identificados pelo impulso de exploração dos novos campos de trabalho para o historiador. A abertura do $\mathrm{NCPH}$ para outros agentes evidenciou desde cedo, porém, as fendas que contrastavam com a ambição de uma identidade unificadora para esses profissionais. Os chamados federal historians - historiadores que já vinham trabalhando para o governo federal dos Estados Unidos -, por exemplo, viam com maus olhos o discurso dos jovens colegas em favor da ocupação de espaços que não estariam propriamente vazios. Como Denise Meringolo escreveu, "historiadores federais [...] sentiam uma desconexão profunda entre o trabalho deles e os objetivos da história pública, e acreditavam que o movimento de história pública os marginalizou mais ainda" (Meringolo, 2012, p. xviii).

Meringolo remete à sonora hostilidade entre o NCPH e a Sociedade pela História no Governo Federal, ou Society for History in the Federal Government (SHFG), também criada em 1979, e a uma famosa controvérsia envolvendo Jack M. Holl, então historiador do Departamento de Energia, que em 1999 havia escrito:

Não acredito que as preocupações profissionais de historiadores federais possam ser satisfeitas por uma organização esmagadoramente dominada por historiadores acadêmicos que consideravam nosso emprego como 'carreiras alternativas' e nos despejavam numa categoria profissional de 'história pública', o jeito de eles abreviarem 'história não acadêmica'. (apud Meringolo, 2012, p. xviii-xix) 
Ter seu trabalho compreendido como uma "carreira alternativa" - expressão muito difundida na literatura da área - foi motivo de muito rancor para esses historiadores federais. Na visão deles, por ser dominado por acadêmicos, o movimento de história pública não poderia fazer outra coisa a não ser legitimar a ampliação de seus próprios domínios e lançar todos os outros historiadores em uma vala comum de "não professores". "Por um curto tempo, e de maneira ineficaz, tentei conter a corrente ascendente do movimento de história pública de Kelley no governo federal”, voltou a escrever Holl em 2008, ainda carregado de ressentimento. "Por que precisávamos de um termo singularizador como história pública para definir o que eu considerava um fenômeno tão ordinário?” (Holl, 2008, p. 32).

Manifestando forte incômodo com a primeira definição de história pública oferecida por Robert Kelley (novamente, "emprego de historiadores e do método histórico fora da academia”), Holl argumentava que ela colocaria historiadores em pé de igualdade com profissionais como "advogados, cientistas políticos, economistas, analistas de políticas, amadores, talvez até romancistas históricos" (Holl, 2008, p. 31). Ao mesmo tempo, sugeriria que qualquer pessoa poderia ser abrangida na categoria, incluindo-se aí "todos os professores que aceitassem um cachê por uma palestra ou que fossem pagos por um artigo numa enciclopédia" (p. 32). Se um advogado que tem um escritório, e não uma sala na universidade, não chama a si mesmo de "advogado público" ou "advogado profissional”, perguntava-se Holl, por que no caso da História deveria ser diferente? Ao mesmo tempo, e em certo sentido de maneira contraditória, Holl conclamava seus colegas de ofício a abandonarem a ideia de que haveria um "solo comum" entre a história pública e a história acadêmica: "Celebrar esta tradição do 'solo comum”, escreve Holl, "mascara as diferenças culturais fundamentais entre historiadores que praticam e historiadores que ensinam [...]. Eles são espécies diferentes que trabalham dentro de um paradigma profissional distinto" (Holl, 2008, p. 30).

Vencida pela corrente majoritária da história pública estadunidense, a posição de Holl, no entanto, aponta para uma das contradições cruciais do movimento, encampado (como acontece até os dias de hoje) e até mesmo liderado por acadêmicos com pouca ou nenhuma atuação pública. O emprego dúctil da expressão tem servido, não raro, a acadêmicos e coletivos que, embora parcamente afinados com a prática da história pública, dela se valem em esforços de 
afirmação profissional, em ocasiões nas quais a etiqueta apresenta-se como uma janela para a obtenção de financiamentos, ou em conjunturas nas quais alguma forma de engajamento público seja encorajada. Reproduzindo-se em outros contextos na medida da eclosão de movimentos de história pública internacionalmente, esse quadro ainda não foi seriamente discutido no contexto dos Estados Unidos.

\section{FORMAÇÃO PARA O TRABALHO E RETÓRICA DE RESULTADOS}

A partir do NCPH ou de seus arredores, outros artefatos surgiram visando contribuir para o fortalecimento e a popularização dos programas de história pública - e para estabilizar um conjunto de princípios, mais ou menos explícitos, sobre o qual a comunidade se assenta. Entre 1981 e 1985, a organização publicou o boletim quadrimestral Teaching Public History [Ensinando história pública], voltado ao intercâmbio de experiências e ao estímulo à criação de novos programas de ensino de história pública em departamentos de história. Em 1986, divulgou sua primeira listagem dos programas americanos, que ganhou segunda edição 10 anos depois, sob o título A Guide to Graduate Programs in Public History [Guia de programas de pós-graduação em história pública], e encontra-se agora disponível em meio digital, com revisões periódicas. ${ }^{5}$ Em 2015, o NCPH criou um comitê para o desenvolvimento de diretrizes para os programas, aprovadas e publicadas em 2016. ${ }^{6}$ Também em 2015 (com revisão em 2018), publicou um guia acessível e ilustrado para estudantes, intitulado The Public History Navigator: How to Choose and Thrive in a Graduate Public History Program [O navegador da história pública: Como escolher e se sair bem em um programa de pós-graduação em história pública]. A primeira parte os auxilia a localizar e escolher um programa adequado aos seus interesses, bem como a refinar o entendimento da formação que irá obter: "Em que um programa de história pública difere de programas de estudos museológicos ou de preservação histórica?”, por exemplo. A segunda estimula a adoção de práticas, durante a formação, que possam contribuir para seu desenvolvimento e sucesso profissional - que vão desde a participação em conferências à adoção de "mentores" e ao desenvolvimento de uma "marca pessoal"? ${ }^{7}$ 
Recomendações como essas não distam da retórica cultivada pelos programas, inseridos em um sistema universitário extremamente competitivo, em que o pagamento de matrículas e anuidades é crucial para a sobrevivência da maioria das instituições. Como todos os cursos - seja em instituições públicas, seja em instituições privadas - são pagos e dependem em grande parte das receitas que geram, o empenho na atração e na retenção de alunos é generalizado. Desdobra-se na diligência de professores que, inseridos na lógica do ensino superior pago, partem ativamente na prospecção de estudantes durante congressos, por exemplo, e também no discurso fortemente voltado à preparação para o mercado de trabalho, com promessas de resultados. Nos impressos de divulgação desses programas, nada soa mais forte do que a propaganda da educação vocacional. ${ }^{8}$ O folder do Programa de História Pública da State University of New York em Albany, por exemplo, enfatiza a "preparação para o emprego" listando algumas das instituições nas quais seus egressos trabalham, e insistindo que:

A depender dos cursos escolhidos, os estudantes se preparam para empregar-se em sociedades históricas, museus, arquivos e agências similares; em agências envolvidas no planejamento de políticas públicas; ou em organizações que recorrem a tecnologias digitais e a tradicionais e novas mídias para pesquisar, preservar e comunicar o passado.

Já a University of Nebraska, em Kearney, que oferece um programa de Mestrado em História com ênfase em história pública, afirma preparar estudantes "para carreiras em instituições do estado, do condado e locais, incluindo: curadores, intérpretes históricos, preservacionistas históricos, consultores, diretores de museus, historiadores do governo, historiadores orais, administradores de recursos culturais, e inúmeras outras vagas". Em um pequeno marca-páginas, a Central Connecticut State University escolhe este como o único tema a abordar: "Nossos graduados em histórica pública trabalham em museus, agências governamentais e em um conjunto de organizações sem fins lucrativos e privadas".

Em concordância com isso, enfatiza-se também o oferecimento de uma formação eminentemente prática, com treinamento em campo e participação em estágios. "Os estudantes de pós-graduação do Mestrado em História Pública na NC State não ficam apenas sentados ouvindo palestras; eles vão 
além da sala de aula para colocar a história em prática”, afirma o panfleto do programa de história pública (que inclui doutorado) da North Carolina State University. Já o programa de mestrado em História oferecido em conjunto pelo College of Charleston e pelo The Citadel, The Military College of South Carolina, que se define como um programa que "forma estudantes para carreiras empolgantes no campo", afirma que "nos últimos 2 anos, criamos novas disciplinas práticas em parceria com instituições de história pública”. Alguns desses programas, aliás, são inteiramente oferecidos em cooperação, de modo a facilitar os estágios e a empregabilidade dos estudantes, mas também a diversificar o corpo docente, incluindo instrutores atuantes no mercado de trabalho. É o caso do Masters in Heritage Studies and Public History (HSPH), da University of Minnesota, oferecido em parceria com a Minnesota Historical Society, que funciona não só como fonte de onde parte dos docentes do curso são extraídos, mas também como um espaço de trabalho onde os alunos realizam um dos dois estágios obrigatórios (ambos remunerados) contemplados pelo programa.

Reincidindo em seu apoio vigoroso aos programas e, de modo mais amplo, à pedagogia da história pública, o NCPH criou e liderou recentemente uma Força-Tarefa Conjunta para a Educação e Empregabilidade em História Pública, a Joint Task Force on Public History Education and Employment, voltada a estudar detalhadamente a eficácia da formação oferecida por programas de história pública e a inserção de egressos no mercado de trabalho. Sua motivação foi um diagnóstico informal que circulava na área e que foi sumarizado em 2013 por Robert Weyeneth: ${ }^{9}$

(1) Há agora programas de história pública demais em faculdades e universidades, especialmente em nível de pós-graduação. (2) Eles estão produzindo números recorde de novos mestres, provavelmente demais. (3) Esses novos historiadores públicos não estão encontrando bons empregos de entrada no campo. (4) Alguns dos novos pós-graduados não estão encontrando empregos porque eles são mal formados - por novos programas de história pública que lutam para descobrir o que deveriam estar fazendo. (5) Nem mesmo os pós-graduados em programas bem estabelecidos estão conseguindo empregos - porque seus currículos indigestos não se mantiveram atualizados com as realidades da economia do século XXI e da revolução digital. 
Dois surveys conduzidos pela Força-Tarefa chamam atenção tanto pelos sugestivos resultados que apresentam quanto pela dimensão das investigações, evidenciando um investimento massivo na avaliação dos programas e de seu papel no mercado de trabalho para o historiador.

O primeiro deles baseou-se nas respostas oferecidas em 2015 por 401 empregadores para investigar "quais habilidades e conhecimentos são mais valorizados pelos empregadores" e para "identificar tendências nas práticas de contratação". Entre os muitos achados interessantes da pesquisa, identificou-se a habilidade que, segundo os empregadores, terá mais demanda no futuro: a de captação de recursos (48,5\%, em questão de múltipla escolha e multirresposta), e que $55 \%$ consideram indispensável e 33,2\% extremamente valiosa a realização de estágios durante o programa de pós-graduação em história pública. $^{10}$

O segundo survey, conduzido entre abril de 2016 e maio de 2017, contou com a participação de quase 1.500 egressos de programas de história pública que se pós-graduaram entre 1985 e $2017 .{ }^{11}$ A pesquisa refutou a hipótese de que uma crise empregatícia para historiadores públicos estaria se desenrolando, embora tenha mapeado queixas sobre "condições de trabalho, oportunidades em declínio e sacrifícios feitos para obter emprego na área”. Ao mesmo tempo, à luz do primeiro survey, a segunda pesquisa evidenciou que "um título de pós-graduação em história pública pode não ser, por si só, a preparação adequada para uma carreira no campo". Continua o relatório:

Os empregadores esperam consistentemente que os pós-graduados de programas em nível de mestrado sejam historiadores capacitados; tenham alguma familiaridade com habilidades especializadas, como captação de recursos, tecnologia digital ou gerenciamento de projetos; e tenham uma forte experiência aplicada. A influência crescente da tecnologia digital e a dependência cada vez maior da filantropia, por exemplo, levou os empregadores a favorecerem candidatos com alguma formação ou experiência nessas áreas. O mesmo se pode dizer em relação a gerenciamento de projetos, um conjunto de habilidades cuja demanda reflete, em parte, a dependência crescente de consultores externos. Essas mudanças não são exclusivas da história pública. Elas evidenciam pressões sociais e políticas que já têm remodelado muitas organizações e provavelmente continuarão tendo influência por algum tempo. 
Conquanto sejam uma iniciativa admirável, por sua dimensão e ousadia, e possibilitem a discussão fundamentada sobre a formação e o mercado de trabalho para o historiador público nos Estados Unidos, os surveys parecem ser assumidos no relatório como um quadro dado. Um quadro ao qual historiadores e educadores devem se adaptar, a fim de atender à clientela dessa história pública - gerentes, administradores, empregadores, contratantes como sob o slogan "servir bem para servir sempre". Encerrada com a conclusão dos dois surveys, a Força-Tarefa Conjunta para a Educação e Empregabilidade em História Pública faz jus à segunda parte do seu nome, virtualmente ignorando o público como espaço do comum, do coletivo, do socialmente compartilhado. Não almeja alimentar a reflexão sobre o impacto público da história, mas garantir a continuidade de um sistema de ensino baseado no controle de uma prática.

\section{HISTÓRIA PÚBLICA COMO PERFORMANCE}

Deveria ser inusitado que correntes centrais do movimento de história pública estadunidense empregassem esforços para aferir a satisfação de ex-alunos e de empregadores com o treinamento oferecido pelos programas - em vez de, quem sabe, investigar a repercussão pública da atuação dos profissionais formados. Não é. Pelo contrário, a primazia da eficácia relaciona-se intimamente com o princípio sobre o qual esses programas se assentam. Em última instância, eles alteram essencialmente a maneira pela qual um historiador "torna-se" historiador público: por meio do cumprimento de um número de créditos em uma instituição de ensino, não mais a partir da associação entre uma sólida formação humanística e a vivência dos desafios do trabalho profissional em museus, sociedades históricas, arquivos, parques nacionais etc. Esse princípio é traduzido por currículos centrados na formação técnica, orientada à vida profissional - o que representaria uma alegada superação da teoria e da abstração, característica de outras formações em ciências humanas.

As "várias direções" da "educação profissional em história pública" são abordadas por Gerald Zahavi em uma valiosa leitura panorâmica que termina com a sugestão de que um bom programa de história pública deve "preparar os estudantes para uma vida de compromisso com o público" (Zahavi, 2011, p. 62). A despeito das "várias direções" seguidas, a maior parte desses programas possui 
uma disciplina obrigatória de “introdução à história pública”, integrada a um conjunto nuclear de disciplinas que recobrem temas como a genealogia da história pública, noções de memória, história local e patrimônio. Tendem, além disso, a contemplar uma mescla de outras "introduções" (dependentes da ênfase de cada programa: por exemplo, curadoria, museologia, arquivística, história oral, mercado editorial, análise de políticas públicas etc.) e de cursos técnicos (edição de vídeo, escrita criativa, produção multimídia, ferramentas digitais etc.). São, portanto, cursos de pós-graduação que oferecem uma formação generalista.

Além de variados, cabe acrescentar o caráter inespecífico desses cursos. Um pós-graduando na Duquesne University, na Pensilvânia, pode, por exemplo, graduar-se com uma disciplina metodológica obrigatória ("Introdução à História Pública"), uma teórica (como "Museus e Sociedade", entre seis opções), três profissionais (como "Introdução aos Arquivos", "Exposições e Gerenciamento de Museus" e "Métodos de História Oral”, entre sete opções), dois estágios ("Preservação histórica" e "Arquivo", entre seis opções), e mais quatro disciplinas convencionais nas áreas de concentração de história dos Estados Unidos, história europeia e história global/internacional. ${ }^{12} \mathrm{Na}$ University of Wisconsin-Milwaukee, o aluno pode se formar obtendo 12 créditos nas disciplinas estruturantes de história pública ("Introdução à História Pública", "Métodos de Pesquisa em História Local" e "Estágios"), 12 créditos em seminários e colóquios, e 9 a 12 créditos em uma das áreas de especialização ("Estudos Museológicos”, "Arquivos”, "Preservação Histórica”, ou ainda na elaboração de uma dissertação, não obrigatória). ${ }^{13}$ Essa não é uma deficiência desses programas; pelo contrário, é um atributo revelador da dimensão atitudinal - e não disciplinar, embora alguns autores a defendam como uma disciplina ou subdisciplina ${ }^{14}$ - da história pública.

Tal inespecificidade espelha-se em um tipo de publicação que tem ascendido nos últimos anos, diretamente voltado à formação em história pública. ${ }^{15}$ São os textbooks, livros didáticos produzidos para uso no contexto educacional. Nos últimos anos, três desses livros apareceram: Public History: A Practical Guide, de Faye Sayer (2015); Public History Textbook, de Thomas Cauvin (2016a); e Introduction to Public History: Interpreting the Past, Engaging Audiences, de Cherstin M. Lyon, Elizabeth Nix e Rebecca K. Shrum (2017). ${ }^{16}$ Como a face mais recente desse movimento internacional de pedagogização 
da história pública iniciado nos Estados Unidos, esses três livros aproximam-se de guias ou manuais, ambicionando orientar a iniciação de jovens historiadores à prática. A existência dos três - lançados quase que simultaneamente por editoras concorrentes - parece ser embasada pelo princípio de que a prática da história pública requer treinamento, e de que este é necessariamente distinto daquele recebido pelo historiador em sua formação básica. Daí essas obras extraem sua autoridade, e daí elas partem para estender a tarefa de reforço de uma identidade profissional distinta. Se antes os programas e o aparato institucional (ao alcance de poucos) eram os recursos centrais para a promoção do discurso da competência técnica, agora ele se expande a um número virtualmente ilimitado de leitores por meio de livros de viés instrumental.

É notável, no entanto, o paradoxo que esses livros colocam: defendem a história pública como disciplina específica que enseja uma formação diferenciada, mas propõem um treinamento que não é estranho à miscelânea de atividades que já integram o escopo de atuação do historiador. O livro de Cauvin (2016a), por exemplo, divide-se em três partes: (1) "Coletar, administrar e preservar o passado: História pública e fontes”, que trata das fontes e das ferramentas de pesquisa do historiador público: arquivos, manuscritos, museus, preservação histórica, história oral, história familiar; (2) "Fazendo história pública: mídia e prática”, que focaliza as linguagens e as formas de apresentação de resultados: escrita, edição de textos históricos, exposições históricas, produção radiofônica e audiovisual, história pública digital, ambientes imersivos; (3) "Colaboração e usos do passado", que trata da criação de programas de história pública, do conceito de autoridade compartilhada, do historiador como ativista, e do trabalho de consultoria e políticas públicas. Cada uma dessas partes oferece introduções sucintas para os assuntos mencionados, por vezes abreviando práticas bastante complexas. Toda a história oral, por exemplo, é ensinada em 14 páginas - por um lado, insuficientes para a formação integral de um pesquisador atento às dimensões da memória, da narrativa, da cultura, do diálogo; por outro, pouco acrescentando às dezenas de livros especializados que poderiam ser referenciados. Mas, nesse caso, o que restaria para dizer? O leitor de Public History Textbook chegaria ao fim do livro como um generalista, iniciado em várias práticas afinadas com a história pública, sem ser um expert em nenhuma delas. 
Introduction to Public History, de Lyon, Nix e Shrum (2017), persegue estrutura semelhante. Na primeira parte da obra, as autoras valorizam os métodos de pesquisa, o pensamento histórico e a heurística como os vasos comunicantes entre a história acadêmica e a história pública; em seguida, partem para capítulos com inclinação para a prática: "Coletando", "Interpretando e exibindo história", "Envolvendo as audiências", "Colocando a história pública para trabalhar no seu mundo". Fazem-no lançando mão de estudos de caso verdadeiramente interessantes, que evidenciam a função assumida pela história pública em casos controversos, e permitem contato com as soluções encontradas por historiadores nos desafios práticos da história pública. A experiência pretérita das autoras certamente contribui para isso, distinguindo-se assim notadamente do caso de Cauvin, cujo textbook é seu primeiro livro.

O "guia prático" de Sayer (2015) não foge à regra. Inclui capítulos sobre "Museus, arquivos e centros de patrimônio", "Métodos de comunicação em história pública", "Ensinando história", "História comunitária”, "História e mídia", "Políticas, política e história" e "Mídia digital", que sucedem uma introdução ponderada e mais eloquente no tocante às controvérsias da história pública do que seus correlatos. Provavelmente em função da origem e inserção profissional da autora - na Grã-Bretanha, onde a história pública associou-se muito à história oral e à história vista de baixo -, discussões bem-vindas sobre "autenticidade", "entretenimento versus educação", "consumismo" e "propriedade" despontam. Sem mistificação, Sayer preocupa-se com a ênfase colocada não no produto, mas na experiência do consumidor, pelas indústrias de entretenimento, mídia, patrimônio e turismo. "Essa abordagem de história pública orientada ao consumidor levou a dilemas éticos e morais na profissão", diz ela, perturbada pela possibilidade de que "a história pública já não tenha o poder de ser imparcial ou de falar pelos marginalizados, e de que as representações comercializadas do passado ameacem a verdadeira preservação e apresentação da história" (Sayer, 2015, p. 18).

Com contribuições interessantes, úteis e, em alguns casos, verdadeiramente inspiradas, esses textbooks, entretanto, acabam por confirmar a inespecificidade disciplinar e profissional de nosso assunto. À revelia de seus autores, a história pública sai desses livros como um ponto de confluência para práticas, metodologias, temas e temporalidades extremamente diversos - perpassados por uma espécie de "atitude pública”, de "espírito público", de inclinação em 
direção ao público, que passa pelo reconhecimento de uma variedade de fontes, linguagens, estratégias de diálogo, formatos de difusão, soluções comunicacionais, ou mesmo da importância das colaborações interdisciplinares e multiprofissionais. Uma história pública rica, complexa e multifocal, injustamente minimizada por uma performance artificial que exclama que "não se nasce historiador público" (Cauvin, 2016b) para cumprir sua função institucional: a de renovar e reforçar a reivindicação, para o campo dos historiadores públicos, do controle sobre uma profusão de áreas que não são terra de ninguém - mas são, mais propriamente, terra de todos. Nesse caminho, não faltam exercícios de retórica: eles apresentam a história pública como uma variedade mais dinâmica, mais excitante, mais viçosa de história - quase como uma outra prática, isenta do bolor e da ferrugem da antiquada "história acadêmica", elaborada sob medida para cativar novos adeptos dispostos a embarcar no trem-bala da história pública, cujo destino é um lugar onde tudo, tudo, supostamente, é "feito de um jeito diferente".

Esse discurso cava sua especificidade em uma alegada distinção em relação à história como disciplina e como pedagogia, escapando assim de ser absorvido por ela. Busca convencer de que a história pública é uma profissão à qual só se acede a partir da posse de habilidades específicas. Não seria, porém, cabível almejar o contrário: que o espírito público e a dimensão metodológica (comunicativa e colaborativa) da história pública ingressassem decisivamente no conjunto de problemas e desafios de todo e qualquer historiador, tornando a própria retórica da história pública dispensável? Não seria saudável, em vez de uma refundação epistemológica, a formação de um profissional e a constituição de uma cultura disciplinar permanentemente atenta à dimensão pública inescapável à sua atividade?

\section{HistóRIA PÚBLICA EM TEMPOS NEOLIBERAIS}

De um lado, tem-se a privatização da história pública por meio da instituição de um modelo orientado pela venda (seja de onerosas taxas de matrícula e mensalidades ao alcance de alguns, seja de publicações disponíveis a muitos). De outro, tem-se a privatização da história pública na redefinição do sentido mesmo de público, manejado para legitimar a subordinação da pesquisa 
histórica à agenda do empregador. Diante disso, é possível falar de uma história pública crítica?

O historiador estadunidense Richard Cándida Smith (2018), em reflexão recente sobre o movimento de história pública em seu país, também apontou a inespecificidade da história pública - em seu caso, no próprio mercado de trabalho. "Os espaços e as práticas incluídas na rubrica 'história pública' têm pouca coisa em comum além de acontecerem, em sua maior parte, fora da academia" (Cándida Smith, 2018, p. 294), escreveu. Ele também defendeu o posicionamento de universidades como aquelas em que trabalhou - a University of California, Los Angeles, a University of Michigan, em Ann Arbor, e a University of California, Berkeley - de não oferecer cursos de história pública:

Achamos que os padrões que os historiadores acadêmicos usam para avaliar seus trabalhos são aplicáveis para a pesquisa histórica feita em qualquer situação, de modo que a formação de historiadores que acabam trabalhando em museus deveria ser idêntica à dos historiadores que se tornam docentes. $\mathrm{O}$ valor daquilo que é comunicado depende da qualidade da pesquisa e da análise, e, em última instância, de sua conexão com os debates historiográficos em curso.

Retratando os trabalhos desenvolvidos por essas universidades com diferentes parceiros - agências estatais e organizações privadas, indo de entidades filantrópicas a sindicatos e empresas -, Cándida Smith insistiu em alguns dos elementos que faziam de seus trabalhos "histórias públicas" compatíveis com os padrões de integridade da pesquisa histórica. Eles deveriam se tornar integralmente acessíveis, a partir de certa data; preservar a autonomia dos pesquisadores, em vez de perseguir agendas estabelecidas pelos contratantes; e contemplar o conflito e a discordância, invariavelmente indesejados. "Tivemos que lidar, inevitavelmente, com uma ideia inerente às operações cotidianas de organizações privadas nos Estados Unidos: comunicar significa, sempre, publicizar uma história positiva”, ele escreveu. "A noção de que a mudança histórica vem do conflito e da discordância era uma proposição que só trazia problemas" (Cándida Smith, 2018, p. 297).

A leitura da pesquisa histórica universitária não orientada à satisfação do cliente enquanto uma espécie de espaço seguro para a produção de conhecimento crítico e para "a análise da discordância e do conflito que é quase 
sempre desconfortável para a maioria dos governos e das organizações privadas, independentemente de onde se situem no espectro ideológico" (Cándida Smith, 2018, p. 299) traduz a crítica a, e o descompasso com, uma cultura intelectual eficientista, orientada pela realimentação permanente de um sistema no qual a satisfação do cliente é régua e compasso para a formação e o exercício profissional do historiador. É preciso examinar a dimensão que essa cultura eficientista ocupa no território mais amplo da história pública, e em que medida a adesão a modelos tecnicistas de produção de conhecimento abre caminho para a subsequente subordinação do pensamento crítico à aparência simpática e palatável de produtos bem-acabados e para a assimilação, pelo historiador em formação e pelo historiador em seu ofício, dos códigos do mercado de trabalho e das fórmulas das indústrias culturais.

Refletindo sobre o papel da história pública no contexto de mercantilização do ensino superior no Reino Unido, Jerome de Groot (2018) foi uma voz solitária ao levantar questões igualmente pertinentes para muitos contextos: "Será que a história pública oferece uma resistência à mercantilização tecnocrática das universidades, sugerindo um tipo 'diferente' de cidadania? A história pública pode oferecer um meio para se desafiar os modelos de conhecimento neoliberais dirigidos ao mercado?".

A sedutora e bem-sucedida fusão entre o discurso da preparação técnica orientada para o trabalho e a retórica vaga do engajamento público sugerem que não - ou, pelo menos, que nem sempre. A penetração da pedagogia da história pública propugnada pelos programas e publicações estadunidenses impõe a necessidade de uma reflexão permanente. Em 2014, a historiadora chinesa Na Li perguntava-se: "É possível integrar a história pública à preservação urbana, na China? Em última instância, a história pública na China é possível?” (Li, 2014). Ao relatar sua experiência ministrando uma bem-sucedida disciplina de história pública na Chongqing University e listando "sugestões para estabelecer programas de história pública na China”, ela concluía que sim: "a história pública está tomando forma na China". Sua ação subsequente, no entanto, foi a de organizar uma expedição que levou professores estadunidenses ao seu país, para o primeiro Public History Faculty Training Program - sugerindo a inescapabilidade da instrução estrangeira para o pleno desenvolvimento de uma história pública local (Li; Sandweiss, 2016). A historiadora polonesa Joanna Wojdon (2016), por sua vez, defendeu a criação de programas 
de história pública em seu país. Embora argumentasse que os programas tradicionais já existentes devessem passar a exigir as mesmas competências demandadas a um historiador público, justificou sua opção afirmando que "às vezes é simplesmente mais fácil criar um novo programa do que reformar um antigo, com suas tradições, compromissos e determinantes". Em suas colocações pragmáticas, prestava atenção mais às diferenças do que às similaridades entre a história pública e a história "normal":

A história "tradicional" (ou "normal") prioriza a reconstrução do passado e a sua metodologia, ao passo que a história pública escolhe a popularização. Estudantes de história normal aprendem a escrever artigos científicos, enquanto estudantes de história pública praticam a escrita de textos para revistas de história populares, websites e blogs. Os primeiros visitam arquivos e museus para adquirir fontes primárias para suas pesquisas. Os últimos vão até lá para observar a forma pela qual as coleções são apresentadas ao público. Nos debates históricos, os primeiros prestam mais atenção ao conteúdo, enquanto os últimos se concentram na forma.

Além de empobrecer enormemente a própria atividade do historiador seja o "normal", seja o público -, essa visão reitera e reforça um modelo tecnicista e eficientista de história pública que prospera no quadro mais amplo de mercantilização da educação e do trabalho intelectual. Contra ele, a pesquisa e o ensino de história informados pela relevância social deveriam resguardar autonomia para se posicionar. A tecnologização vocabular, a simplificação conceitual, a redução do sentido de utilidade para a História, o privilégio à forma, são instrumentos sedutores, especialmente quando aliados à força concreta e simbólica das instituições de ensino superior e das empresas de difusão e circulação de ideias oriundas do contexto anglo-saxônico. Intencionalmente ou não, aliam-se também a projetos de expansão cultural que miram o lucro e a dominação econômica.

Em seu ensaio "Educação para o lucro, educação para a democracia", Martha Nussbaum (2015) preocupa-se com essa dimensão, apontando o privilégio a um "conhecimento bastante rudimentar da história e da realidade econômica" (Nussbaum, 2015, p. 20) na educação voltada ao crescimento econômico, na qual os educadores 
não desejam que o estudo da história tenha como foco as injustiças de classe, de casta, de gênero e de filiação étnico-religiosa, porque isso vai estimular raciocínio crítico sobre o presente. Nem tais educadores querem que se faça qualquer reflexão séria sobre o avanço do nacionalismo, sobre os prejuízos causados pelos ideais nacionalistas e sobre o modo pelo qual muitas vezes os conceitos éticos ficam anestesiados sob a influência da autoridade técnica. (Nussbaum, 2015, p. 21)

No ensino superior público brasileiro, questões socialmente relevantes como a injustiça e a desigualdade - seriam apaziguadas pela pedagogia da competência, da técnica e da forma? A dimensão do conflito e da controvérsia, inerente aos estudos históricos, seria domesticada e empacotada em narrativas gentis, como Cándida Smith criticou? O potencial crítico da história pública seria assolado pela adesão a fórmulas e linguagens da comunicação pública, que a despolitizariam? Isso parece ser pouco provável, dado que as circunstâncias e motivações para o aparecimento e o desenvolvimento recente da história pública no Brasil (Santhiago, 2018) insinuam um entendimento dessa prática pouco afeito ao corporativismo e ao adesismo. Menos provável ainda se tomarmos como parâmetro a íntima associação da história pública com a prática engajada da história oral - que impulsiona a imersão do pesquisador em uma vivência participativa na realidade do grupo que estuda e com o qual trabalha - e com a Educação, por exemplo. Neste último caso, a história pública tem tido educadores de todos os níveis, quando reiteram a natureza intelectual de seu ofício, como aliados na preservação do pensamento crítico e no enfrentamento do eficientismo educacional.

A potencialização da história pública em contextos educacionais - na sala de aula, em programas de residência pedagógica, em iniciativas no Programa Institucional de Bolsas de Iniciação à Docência (Pibid), em discussões transversais em núcleos do Mestrado Profissional em História (ProfHistória) - pode possibilitar avanços em saídas criativas para lidar com a escassez de recursos humanos e financeiros; na cooperação entre estudantes e profissionais de diferentes áreas para a elaboração de produtos sociais e de intervenções; nas dinâmicas de diálogo com diferentes sujeitos que produzem suas próprias leituras do passado; no significado da história pública dentro da universidade pública, gratuita e de pesquisa; no papel político da história pública em um país no qual a democracia e os direitos fundamentais não estão assegurados. 
O emprego de "materiais inovadores" e apresentados sob "novas linguagens" em sala de aula é apenas a superfície da associação entre história pública e educação. $\mathrm{O}$ fato de que isso se dê no terreno do ensino básico é mais um elemento que confirma o entendimento da história pública não como um campo específico, mas como uma perspectiva de análise da produção histórica e como uma atitude crítica diante do presente, do passado e do futuro. Aqui, a história pública canaliza e amplifica debates sobre a relevância e o papel social da história, do historiador, do ensino e das instituições de história, memória e patrimônio. Não assume como neutro o discurso racionalista, aliado do setor privado, que age como tijolo dentro da construção de uma história pública progressivamente privatizada, baseada no controle e no usufruto, por parte de um grupo limitado de indivíduos e instituições, de uma nova narrativa metodológica. Quando orientada à regeneração de um diálogo cultural amplo, que assume o público como o espaço comum no qual interpretações da história são circuladas e negociadas, a história pública se realiza como um gesto repetido de não pactuação.

\section{REFERENCIAS}

ASHTON, Paul; TRAPEZNIK, Alex (ed.). What is Public History Globally? Working with the Past in the Present. London: Bloomsbury, 2019.

BEATTY, Bob (ed.). An American Association for State and Local History Guide to Making Public History. Lanham, MD: Rowman \& Littlefield, 2017.

CÁNDIDA SMITH, Richard. História pública, por que não? In: MAUAD, Ana Maria; SANTHIAGO, Ricardo; BORGES, Viviane T. (org.). Que história pública queremos? What Public History Do We Want? São Paulo: Letra e Voz, 2018. p. 293-299.

CAUVIN, Thomas. Public History Textbook. New York: Routledge, 2016a.

CAUVIN, Thomas. Why We Should All Become Public Historians. Public History Weekly, v. 4, n. 42, 2016 b.

CAUVIN, Thomas; NOIRET, Serge. Internationalizing Public History. In: GARDNER, James B.; HAMILTON, Paula (ed.). The Oxford Handbook of Public History. Oxford: Oxford University Press, 2017. p. 25-43.

DE GROOT, Jerome. For what it is 'worth'? Neoliberalism and Public History. Public History Weekly, v. 6, 2018.

FARNETTI, Paolo B.; BERTUCELLI, Lorenzo; BOTTI, Alfonso (org.). Public History: discussioni e pratiche. Milano: Mimesis, 2017. 
FISHEL JR., Leslie H. Public History and the Academy. In: HOWE, Barbara J.; KEMP, Emory L. (ed.). Public History: An Introduction. Malabar, FL: Robert E. Krieger, 1986.

HOLL, J. M. Cultures in Conflict: An Argument against 'Common Ground' between Practicing Professional Historians and Academics. The Public Historian, v. 30, n. 2, p. 29-50, 2008.

KELLEY, Robert. Public History: Its Origins, Nature and Prospects. The Public Historian, v. 1, n. 1, 1978.

LEFFLER, Phyllis K.; BRENT, Joseph (ed.). Public and Academic History: A Philosophy and Paradigm. Malabar: Krieger, 1990.

LI, Na. Public History in China: Is it Possible? Public History Review, v. 21, p. 20-40, 2014.

LI, Na; SANDWEISS, M. A. Teaching Public History: A Cross-Cultural Experiment The FIrst Public History Faculty Training Program in China. The Public Historian, v. 38, n. 3, p. 78-100, 2016.

LYON, Cherstin M.; NIX, Elizabeth; SHRUM, Rebecca K. Introduction to Public History: Interpreting the Past, Engaging Audiences. Lanham, MD: Rowman \& Littlefield, 2017.

MERINGOLO, D. Museums, Monuments, and National Parks: Toward a New Genealogy of Public History. Amherst, MA: University of Massachusetts Press, 2012.

MILLER, Page Putnam. National Coordinating Committee for the Promotion of History: The Historical Profession's Advocacy Office. The History Teacher, v. 31, n. 2, p. 240-44, 1998.

NOVICK, Peter. That Noble Dream: The Objectivity Question and the American Historical Profession. New York: Cambridge University Press, 1988.

NUSSBAUM, Martha. Sem fins lucrativos: Por que a democracia precisa das humanidades. São Paulo: WMF Martins Fontes, 2015.

RIDOLFI, Maurizio. Verso la public history: fare e raccontare storia nel tempo presente. Pisa: Paccini, 2017.

SANTHIAGO, Ricardo. Duas palavras, muitos significados: alguns comentários sobre a história pública no Brasil. In: MAUAD, Ana Maria; ALMEIDA, Juniele R.; SANTHIAGO, Ricardo (org.). História pública no Brasil: Sentidos e itinerários. São Paulo: Letra e Voz, 2016. p. 23-35.

SANTHIAGO, Ricardo. Pode-se falar em uma história pública brasileira? In: MAUAD, Ana Maria; SANTHIAGO, Ricardo; BORGES, Viviane T. (org.). Que história pública queremos? What Public History Do We Want? São Paulo: Letra e Voz, 2018. p. 323-330. 
SAYER, Faye. Public History: A Practical Guide. London: Bloomsbury, 2015.

SCHULZ, Constance B. Becoming a Public Historian. In: GARDNER, James. B.; LAPAGLIA, Peter S. (ed.). Public History: Essays from the Field. Malabar, FL: Krieger Publishing Company, 1999. p. 23-40.

WEYENETH, Robert R.; VIVIAN, Daniel J. Public History Pedagogy: Charting the Course: Challenges in Public History Education, Guidance for Developing Strong Public History Programs. The Public Historian, v. 38, n. 3, p. 25-49, 2016.

WOJDON, Joanna. Do We Need Public History Study Programs? Public History Weekly, v. 4, p. 33, 2016.

ZAHAVI, Gerald. Ensinando história pública no século XXI. In: ALMEIDA, Juniele R.; ROVAI, Marta G. de O. (org.). Introdução à história pública. São Paulo: Letra e Voz, 2011. p. 53-63.

\section{NOTAS}

${ }^{1}$ Todas as citações de obras publicadas em inglês foram traduzidas por nós.

${ }^{2}$ Ver: https://shprs.asu.edu/public-history.

${ }^{3}$ Ver: https://history.nmsu.edu/publichistory/.

${ }^{4}$ Cabe apontar, no entanto, que os programas têm tido adesão menor nas instituições de excelência, onde "história pública" tende a ser entendida, no melhor dos casos, como um ponto de vista sobre o lugar do passado na sociedade. Foi principalmente em faculdades privadas menores e nos campi secundários dos sistemas estaduais que eles se enraizaram, $\mathrm{o}$ que se pode explicar tanto pela priorização do diálogo social e com o entorno dessas instituições, quanto pela própria acreditação desse campo de trabalho dentro dos circuitos de maior prestígio universitário. Em outubro de 2018, o anúncio de que a Cornell University - pertencente à chamada Ivy League, que congrega oito universidades privadas de excelência dos Estados Unidos - contrataria um professor de história pública foi considerado pela comunidade especializada como um indício de que a prática começara a penetrar, enfim, nessas instituições.

${ }^{5}$ Disponível em: https://ncph.org/program-guide/.

6 "Best Practices in Public History: Establishing and Developing a Public History Program". Disponível em: https://ncph.org/wp-content/uploads/2016/02/Best-Practices-forEstablishing-and-Developing-a-Public-History-Program.pdf.

${ }^{7}$ Disponível em: https://ncph.org/wp-content/uploads/The-Public-History-Navigator2015-Web.pdf.

${ }^{8}$ Os materiais (folders, panfletos e marca-páginas) mencionados no texto foram recolhidos durante a NCPH Annual Conference, em Hartford, Connecticut, 2019. 
${ }^{9}$ Disponível em: https://ncph.org/history-at-work/a-perfect-storm-part-1/. Weyeneth tende a se opor a esse diagnóstico, mas o apresenta como "observações que ouço regularmente de colegas que respeito" (ver WEYENETH; VIVIAN, 2016).

${ }^{10} \mathrm{O}$ relatório da Força-Tarefa para esse primeiro survey pode ser acessado em: http://bit.ly/ ncphemployeereport.

${ }^{11}$ Os resultados do segundo survey foram lançados em março de 2019, e estão disponíveis em: http://bit.ly/ncphalumnireport.

${ }^{12} \mathrm{O}$ catálogo completo das disciplinas está disponível em: https://www.duq.edu/academics/ schools/liberal-arts/departments-and-programs/history/graduate-programs/ma-in-public-history/curriculum.

${ }^{13}$ Igualmente, o catálogo completo das disciplinas está disponível em: https://uwm.edu/ history/graduate/ma-program/public-history/.

${ }^{14}$ Para uma crítica dessa perspectiva, ver: Santhiago (2016). Como exemplos, tome-se o caso italiano, desejoso de alçar a história pública à categoria de disciplina (RIDOLFI, 2017; FARNETTI; BERTUCELLI; BOTTI, 2017).

${ }^{15}$ Nas décadas que sucederam à eclosão do movimento estadunidense de história pública, a produção bibliográfica sobre o tema tendeu a se concentrar em relatos de experiência, em reflexões sobre os usos públicos do passado, e em debates teóricos e conceituais, não raro de tom inspiracional. Nos últimos 5 anos, tem-se assistido à ascensão de dois novos tipos de publicação: os textbooks e os readers, handbooks ou companions - coletâneas de textos de diversos autores, assinaladas pela intencionalidade específica de oferecer ao leitor uma introdução suficiente à área, a partir de fundamentos dispersos em escritos, em geral, previamente publicados.

${ }^{16}$ Em 2017, a Associação Americana pela História Estadual e Local lançou o Guide to Making Public History, organizado por Bob Beatty (BEATTY, 2017). No entanto, apesar de seu título, o livro não se constitui como um "guia", mas como uma coletânea de relatos de experiências de diferentes autores.

Artigo recebido em $1^{\circ}$ de junho de 2019. Aprovado em 27 de junho de 2019. 